in vivo $31: 501-510(2017)$

doi:10.21873/invivo.11089

Review

\title{
Solid Pseudopapillary Tumor of the Pancreas: A Single-center Experience and Review of the Literature
}

\author{
EFSTATHIOS A. ANTONIOU ${ }^{1 *}$, CHRISTOS DAMASKOS $^{1 *}$, NIKOLAOS GARMPIS $^{1 *}$, CHRISTOS SALAKOS $^{2}$, \\ GIORGOS-ANTONIOS MARGONIS ${ }^{3}$, KONSTANTINOS KONTZOGLOU ${ }^{1}$, STEFANOS LAHANIS ${ }^{4,5}$, \\ ELEFTHERIOS SPARTALIS ${ }^{6}$, DIMITRIOS PATSOURAS ${ }^{7}$, STYLIANOS KYKALOS $^{1}$, ANNA GARMPI ${ }^{8}$, \\ NIKOLAOS ANDREATOS ${ }^{3}$, TIMOTHY M. PAWLIK ${ }^{3}$ and GREGORY KOURAKLIS ${ }^{1}$ \\ ${ }^{1}$ Second Department of Propedeutic Surgery, “Laiko” General Hospital, Medical School, \\ National and Kapodistrian University of Athens, Athens, Greece; \\ ${ }^{2}$ Pediatric Surgery Department, ATTIKON University Hospital, \\ National and Kapodistrian University of Athens, Athens, Greece; \\ ${ }^{3}$ Department of Surgery, Johns Hopkins Hospital, Baltimore, MD, U.S.A.; \\ ${ }^{4} 401$ Military Hospital Radiology Department, Athens, Greece; \\ ${ }^{5}$ Iatropolis Medical Center, CT/MRI Department, Athens, Greece; \\ ${ }^{6}$ Laboratory of Experimental Surgery and Surgical Research, University of Athens, Medical School, Athens, Greece; \\ ${ }^{7}$ Department of Colorectal Surgery, Guy's and St Thomas' NHS Foundation Trust, London, U.K.; \\ ${ }^{8}$ Internal Medicine Department, "Laiko” General Hospital, University of Athens Medical School, Athens, Greece
}

\begin{abstract}
Background: Solid pseudopapillary tumors (SPTs) of the pancreas are a rare occurrence, not exceeding $1-2 \%$ of all exocrine pancreatic tumors. SPT was first described in 1959 as "papillary tumor of the pancreas, benign or malignant" and affects mainly young women, in their second or third decade of age. These tumors are of low malignant potential, unclear pathogenesis, grow gradually and become considerably large before causing symptoms. A typical clinical presentation is often described by affected patients and, in some cases, an SPT is an incidental finding during the time the patient undergoes medical imaging studies for other health issues. SPT is frequently located at the head or tail of the pancreas. Metastases are rare but, when present, affect predominantly the
\end{abstract}

This article is freely accessible online.

*These Authors contributed equally to this study.

Correspondence to: Christos Damaskos, MD, MSc, Ph.D., Postdoctoral researcher, Academic fellow. Second Department of Propedeutic Surgery, "Laiko" General Hospital, National and Kapodistrian University of Athens, Medical School, 17 Agiou Thoma Street, Athens, 11527, Greece. Tel: +30 6948467790, Fax: +30 2132061772, e-mail: x_damaskos@yahoo.gr

Key Words: Solid, pseudopapillary, tumor, neoplasm, pancreas, review. liver. Patients and Methods: We report a series of five SPT cases in female patients 13-47 years old, presenting with almost identical symptoms of upper abdominal discomfort and non-tender palpable mass. Two out of five patients also reported vomiting, nausea and poor appetite as co-existing non-diagnostic symptoms. Only one patient presented without any symptoms. Tumor location and dimensions varied. One patient underwent a pancreatoduodenectomy (Whipple's procedure), while the remaining patients underwent distal pancreatectomy with concomitant splenectomy. Results: Perioperative morbidity and mortality was zero. All five patients are disease-free at a follow-up from 3 months to 13 years. Histopathology reports supported the diagnosis of SPT and no metastatic disease was present in any of the patients. Conclusion: The overall prognosis of SPT of the pancreas is excellent due to its favorable biological features, even in the presence of distal metastasis. Although surgical resection is often curative, a close follow-up is advised in order to diagnose a possible local recurrence or distal metastasis and choose the proper therapeutic option for the patients.

Solid pseudopapillary tumor (SPT) of the pancreas is a rare pathologic entity first described by V.K. Frantz in 1959 (1). Most SPTs of pancreas have been described as benign in nature, although $10-15 \%$ of SPT of pancreas shows malignant behavior and metastases (2). SPT of pancreas is a rare neoplasm that accounts for less than $2 \%$ of exocrine 

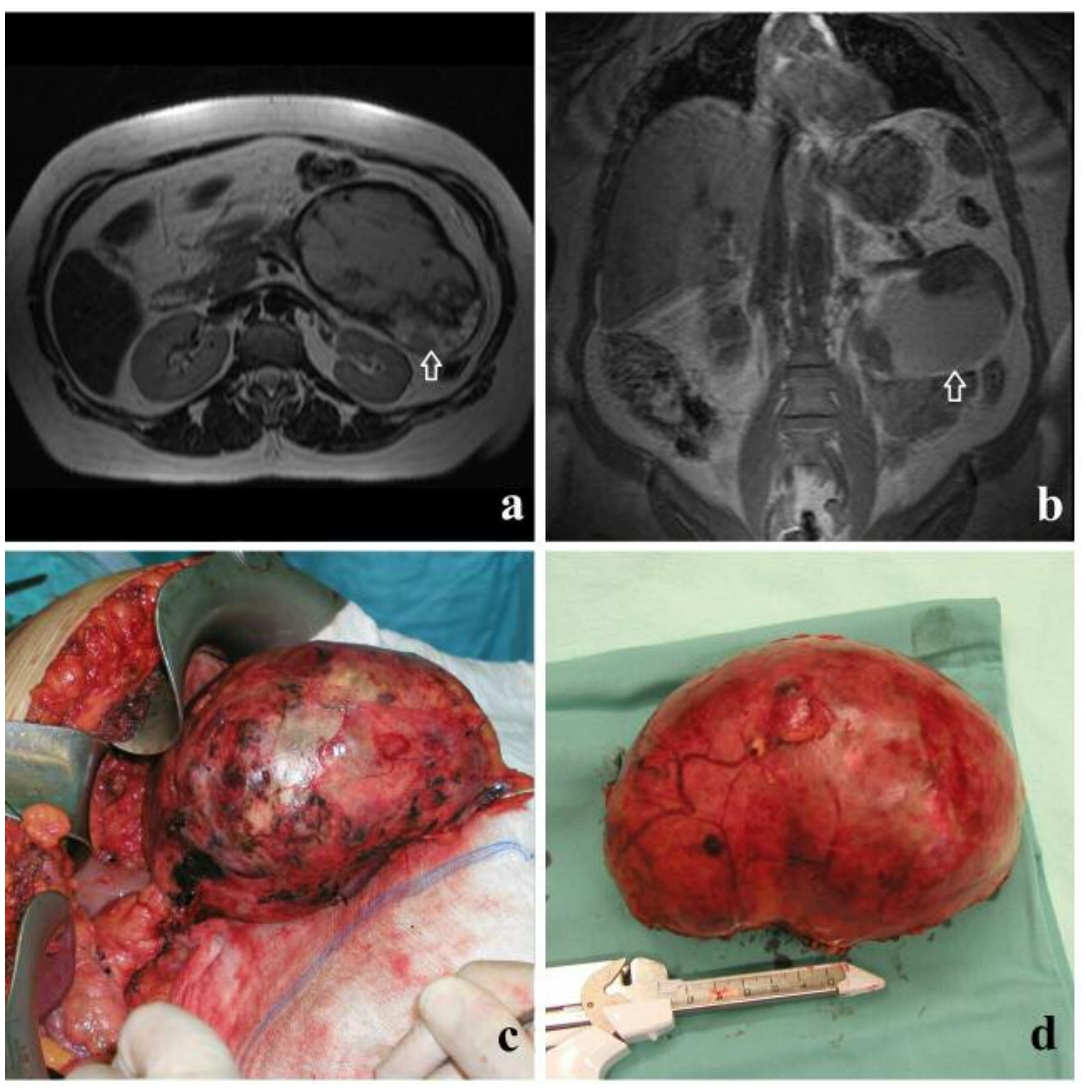

Figure 1. A 16-cm solid pseudopapillary tumor (SPT) located in the body/tail of pancreas. a, $b$ : Non-gadolinium-enhanced abdominal magnetic resonance imaging (MRI) (coronal and sagittal images) revealed a heterogeneous well-defined $13.5 \times 10 \times 8 \mathrm{~cm}$ mass involving the pancreatic tail; $c$ : Encapsulated cystic tumor with hemorrhagic, friable content located in the pancreatic tail; $d$ : Gross appearance of the resected solid pseudopapillary tumor.

pancreatic neoplasms (3-7). However, it has been recognized with increasing frequency in recent years as noted by Stömmer et al. (8). Specifically, with the widespread use and improvement of imaging techniques, these tumors are now being recognized at an increased frequency. Of note, the origin of these neoplasms has not yet been clarified. These neoplasms have a low malignant potential and usually occur in adolescent girls and young women (age range=8-67 years; mean=35); men are rarely affected (4,9-12). Although it is thought that these tumors usually affect people of Asian or African-American origin, SPT can occur in patients of all races $(13,14)$. SPTs are usually characterized by a long asymptomatic period and either found incidentally on routine physical examination or cause atypical symptoms, occasionally after abdominal trauma (9, 15). Atypical symptoms include abdominal pain or discomfort, vomiting and other gastroenteritis-like symptoms. Jaundice is rare, even in tumors that originate from the head of the pancreas and there is no associated functional endocrine syndrome (16). Liver is found to be the organ mostly affected by SPT metastases, but these occur rarely $(9,17-19)$. We report five cases of non-metastatic SPT identified since 2003 with follow-up and a review of the literature.

\section{Case Presentation}

Case 1. A 47-year-old female presented to our Department with persistent left upper abdominal quadrant (LUQ) discomfort for four months. Her previous medical history included diabetes, four abortions and two uncomplicated deliveries. She denied any change in bowel habits or weight loss. Physical examination revealed mild epigastric tenderness and a palpable mass approximately $10 \mathrm{~cm}$ in diameter extending from LUQ to right upper quadrant (RUQ). Routine laboratory tests, including tumor marker levels, were within normal range. Abdominal ultrasonography (US) reported a heterogeneous semisolid mass with cystic components. Abdominal coaxial tomography $(\mathrm{CT})$ revealed a well-defined $13.5 \times 10 \times 8 \mathrm{~cm}$ mass. The mass involved the pancreatic tail and was heterogeneous in consistency. Arterial 


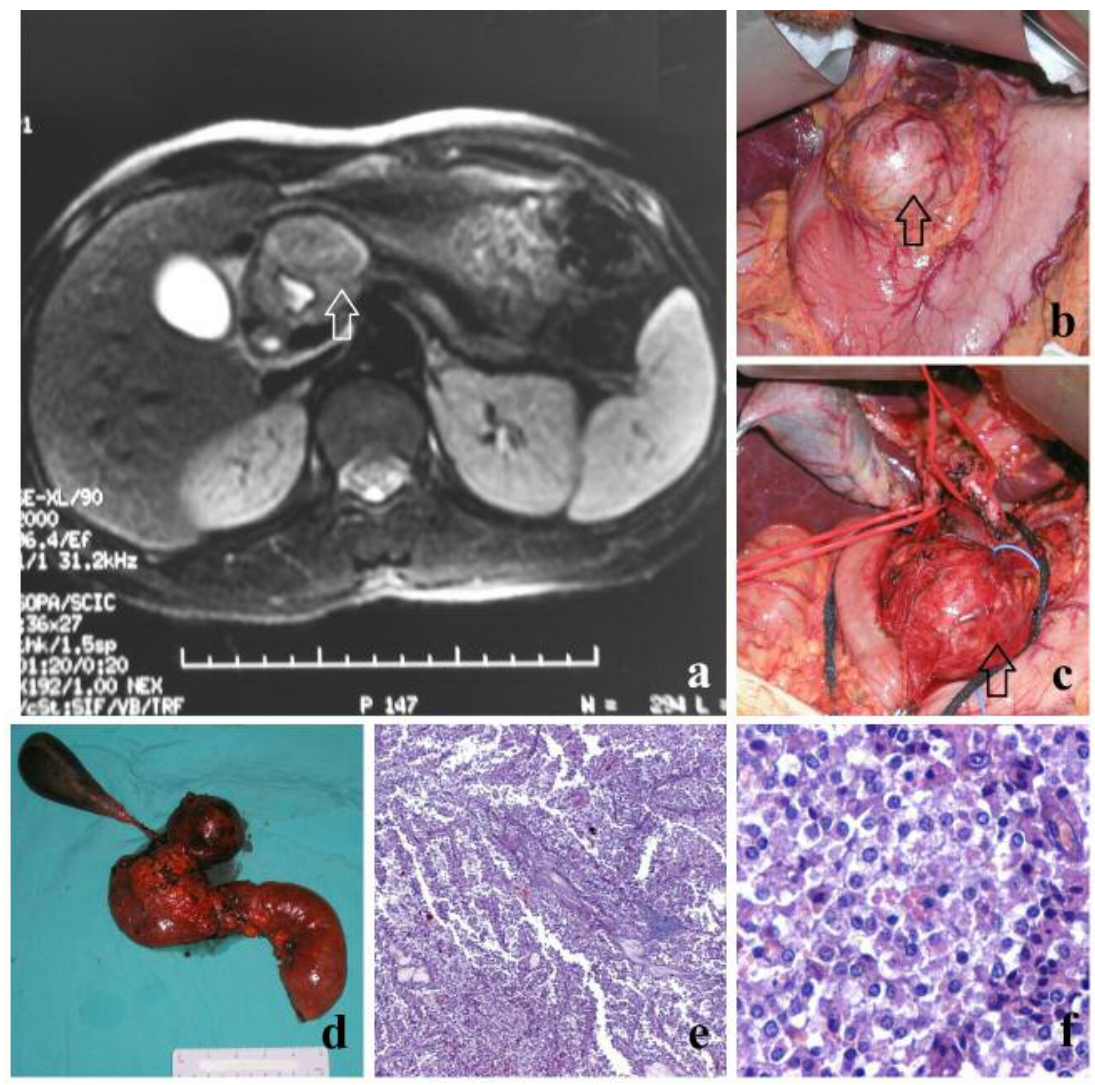

Figure 2. A 6-cm solid pseudopapillary tumor (SPT) located in the head of pancreas. a: Abdominal coaxial tomography (CT) reported a $3.5 \times 4.8 \times 4.2 \mathrm{~cm}$ heterogeneous mass connected to the pancreatic head with loci of tissue necrosis in both the center and the periphery of the mass; $b, c:$ Encapsulated tumor with hemorrhagic cystic and yellowish solid areas; $d$ : Specimen of resected pancreatic head with the tumor, duodenum and gallbladder; $e$ : Neoplastic tissue showing solid and pseudopapillary growth pattern and poorly cohesive monomorphic cells (hematoxylin and eosin (H\&E), $\times 50) ; f: N u m e r o u s$ intracellular hyaline globules $(H \& E, \times 400)$.

and venous Doppler US showed the close relationship between the mass and the splenic vein. Magnetic resonance imaging (MRI) of the abdomen demonstrated a well-defined lesion with heterogeneous signal intensity on T1- and T2weighted images, which reflects the complex nature of the mass (Figure 1a and b).

An explorative laparotomy was performed revealing an encapsulated mass in the body and tail of pancreas that involved the splenic artery and vein. Distal pancreatectomy with concomitant splenectomy was performed (Figure 1c and d). Histopathology reported a SPT of the pancreas without invasive growth pattern, suggesting a lesion of benign behavior. The tumor cells had strong expression of neuronspecific enolase (NSE), CD10, CD56, synaptophysin and progesterone receptors (PRs), while chromogranin A $(\mathrm{CgA})$ was not expressed. No tumor cells were present in the excised lymph nodes. The postoperative course was uneventful. The patient entered a close follow-up program, including physical examination, serum tumor markers estimation (cancer antigen (Ca)19-9, carcinoembryonic antigen (CEA)) and CT scan imaging examination at sixmonth intervals for the first two years and then yearly for the following two years. On a CT scan, one and half year later, an adenoma was found at the right adrenal gland, $4.3 \times 1.7 \mathrm{~cm}$ in size. Patient underwent a right adrenalectomy with a right flank incision. Histology showed nodular hyperplasia of the adrenal gland. At all follow-up examinations to date (13 years postoperatively), the patient remains fit and healthy.

Case 2. A 28-year-old female presented with RUQ pain irradiating to the right shoulder and arm, especially during night hours while sleeping. The patient was unable to report when the symptoms first started but reported that the symptoms worsened in the last two months. Her past medical history included diabetes mellitus type I and two uncomplicated pregnancies/deliveries. Her laboratory results were within normal range. No weight or appetite loss was reported. Physical examination did not reveal any 

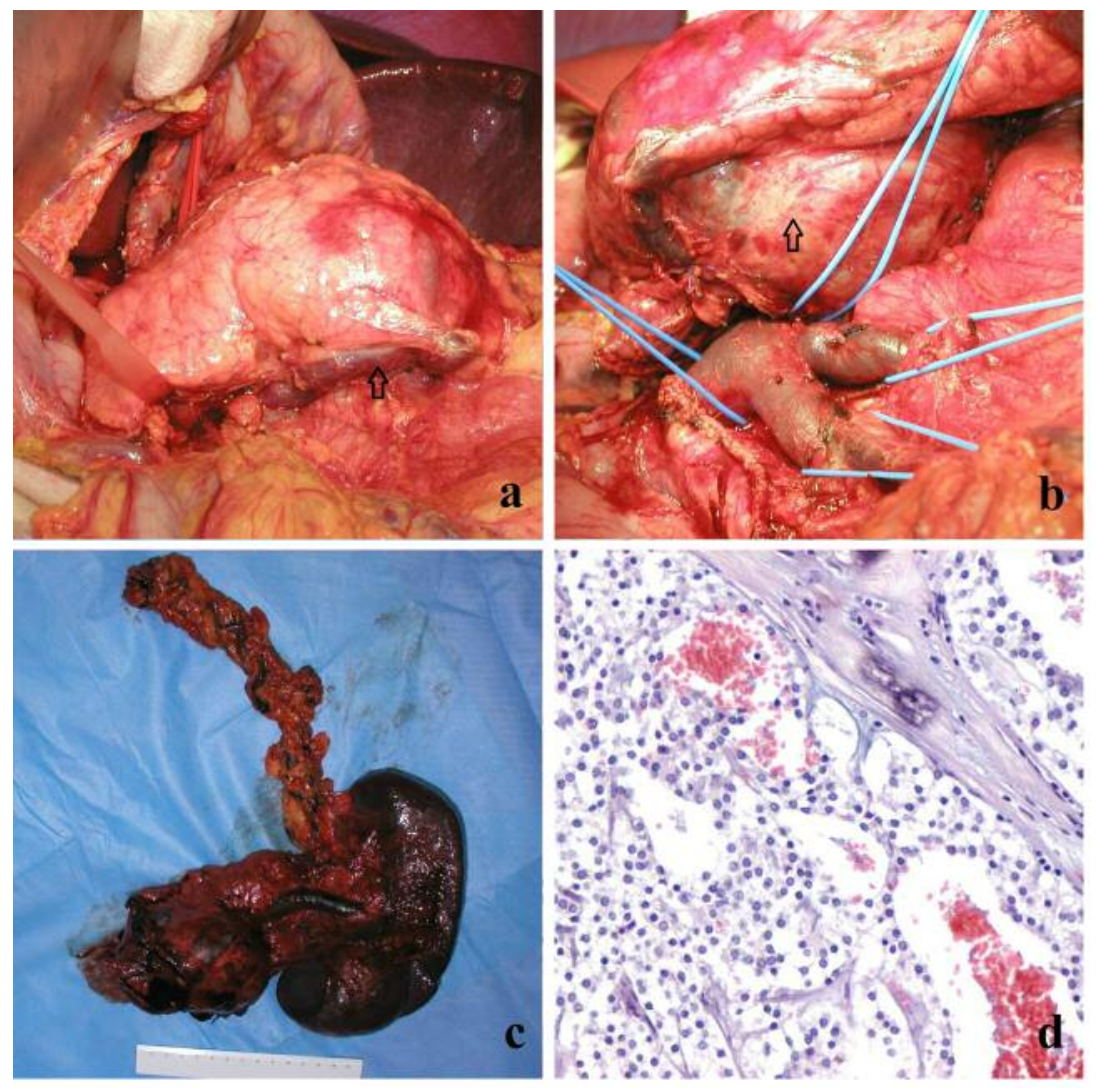

Figure 3. An 8-cm solid pseudopapillary tumor (SPT) located in the body/tail of pancreas. a: The SPT was found to occupy the largest part of the posterior surface of the pancreas, arising from the neck and developed towards to the body and tail of the pancreas; b: Splenic vein (SV) went through the tumor, with the late reaching the join of splenic vein to superior mesenteric vein (SMV); $:$ Gross appearance of the SPT and spleen after complete resection; $d$ : Neoplastic cells with clear cytoplasm and hyalinized fibrous bands (hematoxylin and eosin $(H \& E), \times 100)$.

pathological findings. Patient underwent an abdominal US scan that reported a $3.5 \times 4.8 \times 4.2 \mathrm{~cm}$ heterogeneous mass connected to the pancreatic head with loci of tissue necrosis in both the center and the periphery of the mass. Abdominal $\mathrm{CT}$ and MRI scans (Figure 2a) supported the US findings infarcts.

A Whipple's procedure was performed (Figure 2b-d) and histopathology reported an SPT of the head of the pancreas that measured $5.5 \times 4.5 \times 3.5 \mathrm{~cm}$ in size, which was covered with membrane and developed partially outside of the pancreas, characterized by numerous loci of tissue necrosis and evident cystic degeneration (Figure 2e and f). Excised lymph nodes were free of tumor cells. The postoperative course was uneventful. The patient entered the same followup program as the above-mentioned patient. To date, 4 years postoperatively, the patient remains fit and healthy.

Case 3. A 28-year-old female was referred to our General Surgery Department with persistent upper abdomen discomfort after having a recent episode of possible acute gastroenteritis. Prior to this referral, the referring physician had requested an abdominal US scan that showed a large epigastric mass connected to the pancreatic tail. Past medical history consisted of breasts' cosmetic surgery and nasal septum correction. At the time of the diagnosis, the patient was 4 weeks pregnant. Abdomen CT and MRI scan reported a heterogeneous mass of $8 \times 9 \times 6 \mathrm{~cm}$ in size connected to the posterior surface of the pancreatic tail and adjacent to the left renal vein and the stomach. Numerous loci of tissue necrosis and hemorrhage within the mass were also seen. The MRI scan also reported splenomegaly without infarcts.

As the patient was not aware of the pregnancy and she had received ionizing radiation during the CT scan, she decided to have an abortion based on medical indications. The patient underwent distal pancreatectomy with concomitant splenectomy. Intra-operatively, the mass was found to occupy the largest part of the posterior surface of the pancreas, arising from the neck and developed towards to the body and tail of the pancreas (Figure 3a-c). Because the tumor approached the junction of the splenic vein (SV) to 

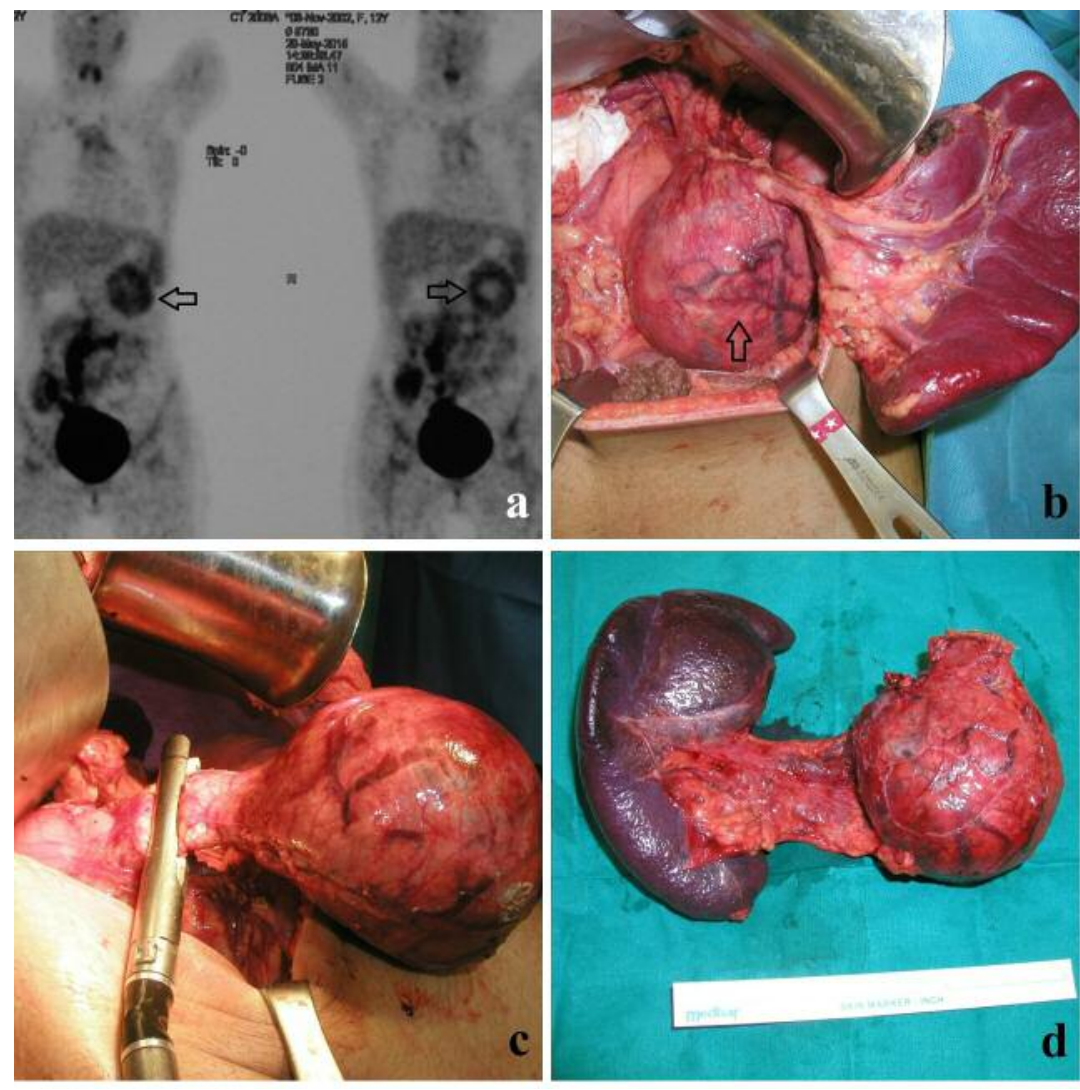

Figure 4. An 1.5-cm solid pseudopapillary tumor (SPT) located in the body of pancreas. a: Positron emission tomography (PET) study showing increased uptake of ${ }^{18} F$-fluorodeoxyglucose $(F-18 F D G)$ in the periphery of the pancreatic tumor (standardized uptake values (SUV) max $\left.=3.0\right)$; $b$ : SPT involving the splenic artery; $c$ : Circumscribed brown-yellow tumor with solid and friable areas; $d$ : Gross appearance of the resected SPT and spleen after complete resection.

superior mesenteric vein (SMV), the SV was cut at its junction with V-shape from SMV-portal vein and a transverse reconstruction was performed with 5-0 polydioxanone suture (PDS). The postoperative course was uneventful. The patient entered the already mentioned follow-up program. The excised mass was well-defined in a pseudocapsule and loci of hemorrhage were present in it. Histology revealed a neoplastic tumor of $8 \times 6 \times 3.8 \mathrm{~cm}$, well encapsulated and partially prompting out of the pancreas, occupying almost the body and tail of it. Immunohistochemistry of the neoplastic cells, showed strong diffused expression of PR, CD10 and vimentin, whereas, in extended area, E-cadherin loss was noticed. $\mathrm{CgA}$ was not significant. Histology report concluded that the mass was an SPT without signs of malignancy (Figure 3d). Excised lymph nodes had no signs of metastasis. Fourteen months postoperatively, patient remains healthy and fit.

Case 4. A 13-year-old female presented with meteorism and eructation dating since three months. The symptoms were present only in standing position and were gradually worsening. Patient did not report any pathology in the past and she had been otherwise fit and well. Blood biochemistry and total blood count were within normal values. An abdominal US scan showed a mass of $8.7 \times 6.8 \times 7.3 \mathrm{~cm}$ in size, occupying the retroperitoneal space adjacent to the tail of the pancreas. An abdominal CT scan revealed a well-defined spherical mass, compressing the splenic artery and the major curvature of the stomach. The intravenously administered contrast was irregularly uptaken by the tumor, excluding the cystic elements of the latter. Contrast-enhanced MRI further supported the findings. Positron emission tomography (PET) study showed increased uptake of $18 \mathrm{~F}$-fluorodeoxyglucose (F-18 FDG) in the periphery of the tumor (standardized uptake values $(\mathrm{SUV})_{\max }=3.0$ ) (Figure 4a).

The patient underwent distal pancreatectomy with concomitant splenectomy (Figure 4b-d). The postoperative period was uneventful. Histopathology reported no signs of mitosis or malignancy, with identical tumor cells consisting of round nuclei and clear cytoplasm. These cells appeared to 

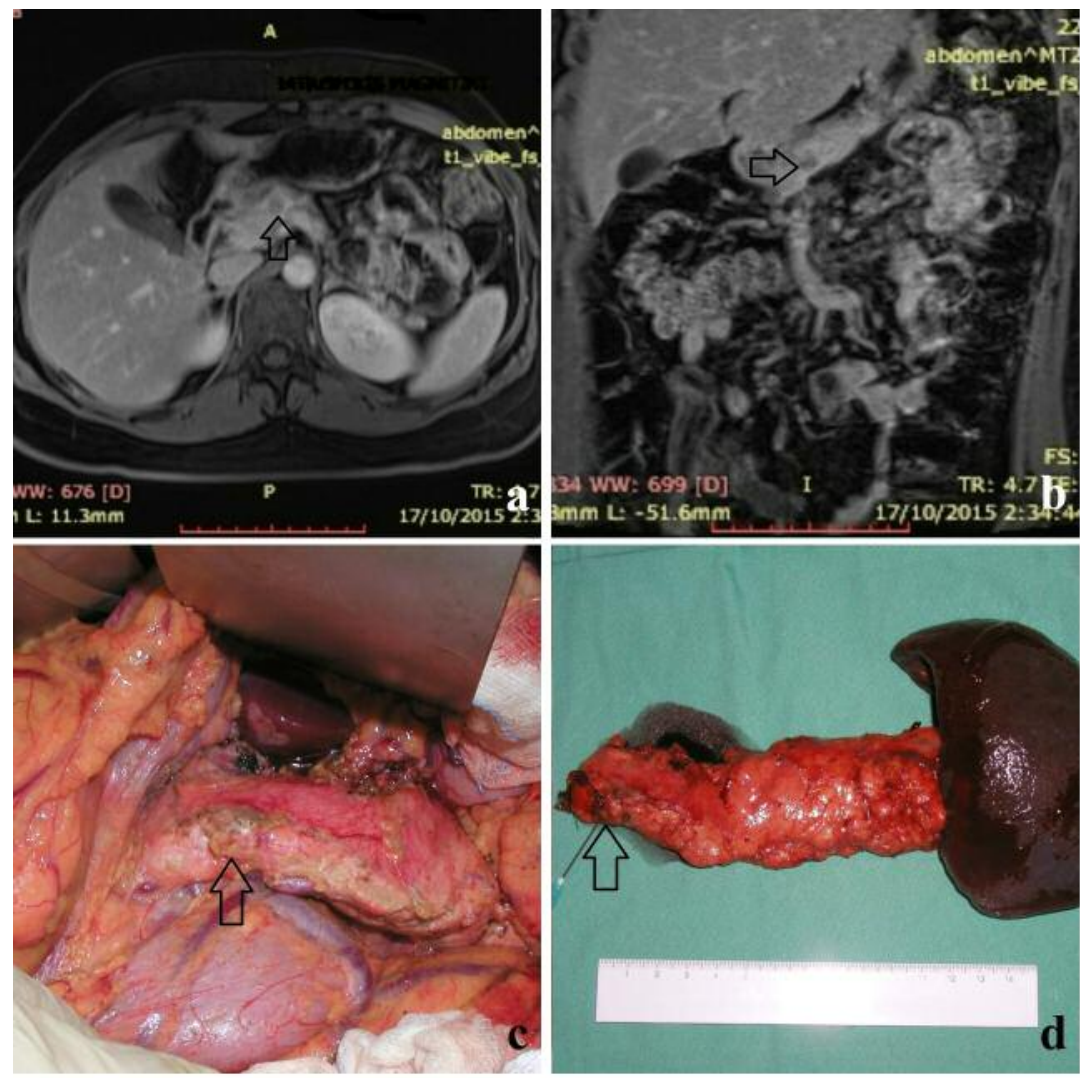

Figure 5. An 8-cm solid pseudopapillary tumor (SPT) located in the body/tail of pancreas. a, $b$ : Abdominal magnetic resonance imaging (MRI) (coronal and sagittal images) reported a 11.6-mm focal lesion situated anterior to the spleno-portal vein junction; c: Encapsulated tumor with microcystic cut surface in the body of the pancreas; $d$ : Gross appearance of the resected SPT and spleen.

be densely packed with eosinophilic material scattered inbetween the cell packs. Immunohistology reported expression of vimentin, CD56, synaptophysin, PRs and $\beta$ catenin. Based on these features, SPT was diagnosed. The spleen and all excised lymph nodes were negative for metastasis. At 12 months of follow-up, the patient is fit and well without any signs of disease relapse.

Case 5. A 29-year-old female was referred to our Department for treatment of a solitary tumor located in the neck of the pancreas. The lesion was an incidental finding of an abdominal US performed for a recent upper urinary infection. The patient did not report any abdominal symptomatology. Patient's past history included hypothyroidism, oral leukoplakia and multiple urinary infections during the last 2 years. Clinical examination and routine laboratory tests did not reveal any abnormal findings. Abdominal MRI reported a $11.6 \mathrm{~mm}$ focal lesion situated anterior to the spleno-portal vein junction (Figure 5a and b). Endoscopic ultrasound-guided fine needle aspirating biopsies
(EUS-FNA) were also performed revealing a nonhomogeneous $12 \times 11 \mathrm{~mm}$ lesion at the neck of pancreas without vessels in fine flow Doppler. FNA histology showed cytomorphology and immunohistochemistry features of SPT. Patient underwent distal pancreatectomy combined with splenectomy (Figure 5c and d). Histopathology confirmed the existence of a SPT of the neck of the pancreas. Patient's postoperative course was uneventful and she was discharged on the 7 th postoperative day. She has been free of any symptoms since, four months postoperatively.

All patients' data with tumor characteristics and procedures details are presented in Table I.

\section{Discussion}

SPT of the pancreas is a rare pancreatic tumor that accounts for $5 \%$ of cystic pancreatic tumors and $1-2 \%$ of exocrine pancreatic neoplasms (20). This tumor was first described by Frantz in 1959 as "papillary tumors of pancreas, benign or malignant" (1). Ectopic pancreatic tissue can also be affected 
Table I. Clinical and pathologic features of the reported cases of non-metastatic solid pseudopapillary tumors (SPTs).

\begin{tabular}{|c|c|c|c|c|c|c|c|c|c|c|c|}
\hline \multirow{2}{*}{$\begin{array}{l}\text { SPT } \\
\mathrm{n}=5\end{array}$} & \multirow{2}{*}{$\begin{array}{l}\text { Age/ } \\
\text { Gender }\end{array}$} & \multirow{2}{*}{$\begin{array}{l}\text { Size } \\
(\mathrm{cm})\end{array}$} & \multirow[t]{2}{*}{ Site } & \multirow[t]{2}{*}{ Imaging } & \multirow[t]{2}{*}{ Operation } & \multirow[t]{2}{*}{ Macroscopy } & \multicolumn{4}{|c|}{ Histology } & \multirow[t]{2}{*}{ Follow-up } \\
\hline & & & & & & & Pattern & $\begin{array}{c}\text { Cell } \\
\text { features }\end{array}$ & $\begin{array}{l}\text { Mitosis/ } \\
10 \mathrm{HPFs}\end{array}$ & $\begin{array}{c}\text { Other } \\
\text { features }\end{array}$ & \\
\hline Pt 1 & $\begin{array}{l}47 \\
y / f\end{array}$ & 16 & $\begin{array}{l}\text { Body/ } \\
\text { tail }\end{array}$ & $\begin{array}{l}\text { US/CT/ } \\
\text { MRI }\end{array}$ & $\begin{array}{c}\text { Distal } \\
\text { pancreatectomy } \\
\text { with } \\
\text { splenectomy }\end{array}$ & $\begin{array}{l}\text { Encapsulated } \\
\text { cystic } \\
\text { tumor with } \\
\text { hemorrhagic, } \\
\text { friable content }\end{array}$ & $\begin{array}{l}\text { Hemorrhagic } \\
\text { necrosis, solid } \\
\text { pseudopapillary } \\
\text { pseudorosettes }\end{array}$ & $\begin{array}{c}\text { Eosinophilic } \\
\text { cytoplasm, } \\
\text { uniform } \\
\text { appearance, } \\
\text { low-grade atypia, } \\
\text { intracellular } \\
\text { hyaline globules }\end{array}$ & None & $\begin{array}{l}\text { Cholesterol } \\
\text { clefts, stroma } \\
\text { hyalinization, } \\
\text { no capsule } \\
\text { or vessel } \\
\text { infiltration, no } \\
\text { LN metastasis }\end{array}$ & $13 \mathrm{y}$ \\
\hline Pt 2 & $\begin{array}{l}28 \\
y / f\end{array}$ & 6 & Head & $\begin{array}{l}\text { US/CT/ } \\
\text { MRI }\end{array}$ & $\begin{array}{c}\text { Distal } \\
\text { pancreatectomy } \\
\text { with } \\
\text { splenectomy }\end{array}$ & $\begin{array}{l}\text { Encapsulated } \\
\text { tumor with } \\
\text { hemorrhagic } \\
\text { cystic and } \\
\text { yellowish } \\
\text { solid areas }\end{array}$ & $\begin{array}{c}\text { Solid } \\
\text { hemorrhagic } \\
\text { pseudocystic } \\
\text { pseudopapillary } \\
\text { pseudorosettes }\end{array}$ & $\begin{array}{c}\text { Eosinophilic } \\
\text { or clear } \\
\text { cytoplasm, } \\
\text { uniform } \\
\text { appearance, } \\
\text { intracellular } \\
\text { hyaline globules }\end{array}$ & 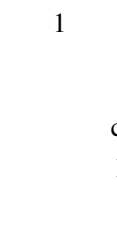 & $\begin{array}{c}\text { Cholesterol } \\
\text { clefts, stroma } \\
\text { hyalinization, } \\
\text { capsule infiltration, } \\
\text { perineural growth, } \\
\text { no LN metastasis }\end{array}$ & $4 \mathrm{y}$ \\
\hline Pt 3 & $\begin{array}{l}28 \\
y / f\end{array}$ & 8 & $\begin{array}{l}\text { Body/ } \\
\text { tail }\end{array}$ & $\begin{array}{c}\text { US/CT/ } \\
\text { MRI }\end{array}$ & $\begin{array}{c}\text { Distal } \\
\text { pancreatectomy } \\
\text { with } \\
\text { splenectomy }\end{array}$ & $\begin{array}{l}\text { Encapsulated } \\
\text { tumor with } \\
\text { cystic and } \\
\text { solid areas }\end{array}$ & $\begin{array}{l}\text { Hemorrhagic } \\
\text { necrosis, } \\
\text { pseudopapillary } \\
\text { pseudorosettes }\end{array}$ & $\begin{array}{c}\text { Clear cytoplasm, } \\
\text { uniform } \\
\text { appearance, } \\
\text { intracellular } \\
\text { hyaline globules }\end{array}$ & 1 & $\begin{array}{l}\text { Cholesterol } \\
\text { clefts, vascular } \\
\text { invasion, no } \\
\text { LN metastasis }\end{array}$ & $14 \mathrm{~m}$ \\
\hline Pt 4 & $\begin{array}{l}29 \\
y / f\end{array}$ & 1.5 & Body & $\begin{array}{c}\text { CT/MRI/ } \\
\text { PET }\end{array}$ & $\begin{array}{l}\text { Whipple's } \\
\text { procedure }\end{array}$ & $\begin{array}{l}\text { Circumscribed } \\
\text { brown-yellow } \\
\text { tumor with } \\
\text { solid and } \\
\text { friable areas }\end{array}$ & $\begin{array}{c}\text { Solid } \\
\text { pseudopapillary } \\
\text { pseudorosettes }\end{array}$ & $\begin{array}{c}\text { Eosinophilic } \\
\text { or clear } \\
\text { cytoplasm, } \\
\text { intracellular } \\
\text { hyaline globules }\end{array}$ & None & $\begin{array}{l}\text { Cholesterol } \\
\text { clefts, stroma } \\
\text { hyalinization, } \\
\text { calcifications, no } \\
\text { LN metastasis }\end{array}$ & $12 \mathrm{~m}$ \\
\hline Pt 5 & $\begin{array}{l}13 \\
y / f\end{array}$ & 8 & $\begin{array}{c}\text { Body/ } \\
\text { tail }\end{array}$ & $\begin{array}{l}\text { MRI/ } \\
\text { EUS }\end{array}$ & $\begin{array}{c}\text { Distal } \\
\text { pancreatectomy } \\
\text { with } \\
\text { splenectomy }\end{array}$ & $\begin{array}{l}\text { Encapsulated } \\
\text { tumor with } \\
\text { microcystic } \\
\text { cut surface }\end{array}$ & $\begin{array}{c}\text { Solid } \\
\text { pseudopapillary } \\
\text { pseudorosettes }\end{array}$ & $\begin{array}{l}\text { Eosinophilic } \\
\text { or clear } \\
\text { cytoplasm }\end{array}$ & None & $\begin{array}{c}\text { Capsular } \\
\text { microinvasion, } \\
\text { no LN metastasis }\end{array}$ & $4 \mathrm{~m}$ \\
\hline
\end{tabular}

Pt, Patient; SPT, solid pseudopapillary tumor; HPFs, high-power fields; US, ultrasonography; CT, coaxial tomography; MRI, magnetic resonance imaging; LN, lymph node; PET, positron emission tomography; EUS, endoscopic ultrasound; f, female; y, years; m, months.

by SPT but it is considered very rare (21). Since SPT's first description in literature, various names have been used to describe this rare lesion, such as solid and cystic tumor of the pancreas, papillary-cystic tumor, solid and papillary epithelial neoplasm and Frantz tumor (3, 4, 22). In 1996, the World Health Organization renamed this tumor as SPT for the international histologic classification of tumor of the exocrine pancreas $(22,23)$. Female predominance has been reported at a ratio of 10:1 and the mean age of presentation is 22 years (24). In consistence with the reported demographics, all our reported patients are females. Three of these were older than the reported mean age of 22 . The fourth patient was 14 years old, a rather unusual age at the time of presentation. The tumor has been found to be more prevalent in Asian and Black populations (25), although it can occur in all races $(13,14)$, and tended to be more fairly aggressive in the older male patients.

Although the pathogenesis of this tumor is unclear, SPT of the pancreas has distinctive pathologic characteristics. On gross examination, the mass is usually large, well-defined and encapsulated and contains a varying combination of loci with tissue necrosis, hemorrhage and/or cystic changes. In all cases reported in this manuscript, the tumor was welldefined with necrosis, hemorrhage and/or cystic changes.

The pathogenesis of this tumor is still controversial. By microscopic analysis, there are two types of cellular arrangements: solid and papillary (22). The histological appearance varies largely in different regions of the tumor. Solid areas consist of sheets and cords of round or ovoid cytologically bland cells arranged on the perimeter of delicate fibrovascular septa (26). Mitotic activity is usually low and true necrosis is uncommon; however, cystic degeneration is very frequent. The pathologic diagnosis is dependent on the presence of solid areas alternating with pseudopapillary pattern and pseudorosettes. SPTs are typically positive for vimentin, NSE, alpha-1-antitrypsin and alpha-1-antichymotrypsin and negative for $\mathrm{CgA}$, epithelial 
membrane antigen and cytokeratine. The presence of the $C T N N B 1$ molecular marker along the absence of KRAS, GNAS, RNF43 and $\mathrm{LOH}$ on chromosome 18 are reported to be a useful stand-alone diagnostic tool but also useful when used in conjunction with specific clinical markers (27).

Most of the patients present with atypical symptoms, including abdominal discomfort, mild abdominal pain, increased abdominal girth, poor appetite and nausea, all related to tumor compression on the adjacent organs $(23,28)$. Atypical clinical presentation is also reported by all our patients, with the majority reporting abdominal discomfort and one reporting irradiation of the abdominal pain to the shoulder and upper right extremity. Acute abdomen can also occur caused by tumor rupture. Physical examination is often normal apart from the presence of an upper abdominal mass. When a palpable mass is presented, the average size of the tumor becomes quite remarkable reaching 8 to $10 \mathrm{~cm}$ in diameter, something seen in the reported patients in our manuscript $(28,29)$. SPTs have not been associated with specific clinical laboratory test findings, including tumor markers $(30,31)$.

Despite the locally aggressive features, the tumor has a low-grade malignant potential and tends to have a favorable prognosis, even in the presence of metastatic disease $(29,31$ 33). Common sites of metastasis are liver, peritoneum, omentum and regional lymph nodes (1). The majority of metastatic patients are male. The correlation between tumor size and malignant potential is controversial $(29,30)$ and the blood vessels' invasion, high degree of nuclear atypia, high mitotic count and presence of large necrotic clusters are considered criteria of high malignancy potential. Nishihara et al. demonstrated aneuploidy in patients with metastases, whereas patients without any sign of malignancy showed diploidy (9).

Our patients presented with SPT of dimensions close to what the literature reports and excised lymph nodes were negative for tumor cells, despite the necrotic lesions within the mass. Invasion of large blood vessels was present in two of our cases.

Morphology of SPT on US, CT or MRI is usually a welldefined large mass that can be predominantly either a thickwalled cystic structure or a solid mass with cystic components. On US, the tumor is a well-defined hypoechoic solid mass, a solid mass with cystic areas or a cystic mass with semi-circularly calcified lesions. Contrast-enhanced CT plays a major role in the diagnostic evaluation of cystic neoplasms of the pancreas. CT usually demonstrates a wellencapsulated heterogeneous lesion with varying solid and cystic components. However, when compared with the MRI, CT has inherent limitations in showing certain tissue characteristics, such as hemorrhage, cystic degeneration or the presence of capsule. MRI has improved our ability to diagnose SPT due to its superior contrast resolution. On MRI, high signal intensity areas are observed in areas of hemorrhagic content. The capsule is usually identified as a thin hypo-intense rim. MRI may also provide information about the resectability of the tumor, something of great importance for proper patient management (34).

Imaging findings in all of our cases were consistent with the above-described morphology of SPT, allowing our team to easily set the right diagnosis.

Echo-endosonography gives the ability of fine-needle puncture biopsy and, therefore, setting a correct preoperative pathologic diagnosis of tumor (35). Angiography, although not routinely indicated, may demonstrate scarce or lack of blood vessels in the pancreatic tumor and help delineate the mass from other involved and adjacent structures (4). Barium meal examinations usually show deformity of the stomach, enlargement of the duodenal loop and narrowing of the duodenal lumen, caused by external pressure from the mass on the organs' wall; these findings, however, are not pathognomonic for setting the diagnosis. In that sense, there is actually no place for barium meal in the preoperative management of these lesions.

Serous microcystic adenoma, mucinous cystic neoplasm, cystic islet cell tumor, pancreaticoblastoma and calcified hemorrhagic pseudocyst are differential diagnostic considerations when a pancreatic mass consists of cystic and solid components $(3,30)$. Immunohistology and molecular markers can assist in reaching the diagnosis (27).

Regarding treatment, complete surgical excision is curative in more than $95 \%$ of patients with SPT that is limited to pancreas. Very small tumors could be enucleated. For larger lesions the type of surgical resection depends on their location. Lesions in the head of pancreas are treated with a pancreatoduodenectomy (Whipple's procedure), while these located in the body and tail are best treated with a distal pancreatectomy. For lesions located in the neck of pancreas, a sparing parenchyma technique like central pancreatectomy may be considered. Such a procedure has the advantage of preserving both the endocrine and exocrine pancreatic function. On the other hand, it is technically demanding and associated with a significantly high complication rate, such as pancreatic leak (36).

Kim and co-authors recently identified tumor size larger than $5 \mathrm{~cm}$ as a predictive factor of high grade malignancy. As such, they proposed that patients with an SPT larger than $5 \mathrm{~cm}$ should undergo complete surgical resection with a formal lymph node dissection (37). Of note, long-term survival is possible even in patients with metastatic disease involving the liver and/or peritoneum. Local invasion, recurrence or limited metastases are not contraindications to resection. For metastases, a general consensus exists that surgical debulking should be performed, which is in direct contrast to oncology principles applied to other pancreatic malignancies. To date, there is limited experience regarding chemotherapy and radiotherapy with or without the presence 
of metastatic disease. Radiotherapy has been suggested in cases of unresectable SPTs, as these tumors appear to be radiosensitive (38).

In our cohort, all patients underwent surgical resection and, in some cases, additional splenectomy. All five patients were not advised to undergo further oncological treatment as sufficient evidence of efficacy does not exist.

Lastly, during pregnancy, SPT is extremely rare and the diagnosis can be difficult to reach as SPT's clinical presentation resembles hyperemesis gravidarum. A number of other more common pregnancy disorders have to be excluded before a physician should consider SPT as a possibility (39). Safe monitoring of the tumor growth rate and the possibility of rupture is suggested by some authors (40). Others support surgical excision of the SPT, since this tumor is responsive to progesterone blood levels $(39,41,42)$. Proper imaging for monitoring during pregnancy can be difficult to obtain and only US and MRI scans (without gadolinium intravenous contrast administration) should be requested as they are reported to be safe for the fetus. However, there remains no consensus on how best to proceed with pregnant SPT patients.

\section{Conclusion}

The overall prognosis of SPT of the pancreas is very good, due to its favorable biological features. These tumors usually affect women in the second or third decade of their life, but other age groups can be affected as well. Clinical diagnosis is impossible as presentation may resemble a number of different pathologies. On the contrary, diagnosis can be based upon proper medical imaging as the SPT morphology is typical in the majority of cases. Prognosis is generally favorable. Although surgical resection is frequently curative and considered the therapeutic method of choice, a close follow-up is advised in order to early diagnose possible local recurrence or distal metastasis and choose for a specific therapeutic scheme for the respective patient.

\section{Ethics Approval and Consent to Participate}

This retrospective single center case study was approved by the local ethics committee of the University Hospital "Laiko", Athens, Greece, and followed the ethical guidelines of Declaration of Helsinki from 1975. The ethics committee waived informed consent because of the retrospective design. All patients have given a written consent for publication.

\section{Availability of Data and Material}

All presented data are available and can be requested from the Authors.

\section{Conflicts of Interest}

The Authors declare that they have no competing interests.

\section{Acknowledgements}

The team of Authors would like to thank Dr. Perdiki M. for performing histopathological examinations.

\section{References}

1 Frantz VK: Tumors of the pancreas. In: Atlas of Tumor Pathology: Fascicles 22 and 28, Section 7. (Washington DC): US, Armed Forces Institute of Pathology, pp. 32-33, 1959.

2 Papavramidis $\mathrm{T}$ and Papavramidis S: Solid pseudopapillary tumors of the pancreas: Review of 718 patients reported in English literature. J Am Coll Surg 200: 965-972, 2005.

3 Cantisani V, Mortele KJ, Levy A, Glickman JN, Ricci P, Passariello R, Ros PR and Silverman SG: MR imaging features of solid pseudopapillary tumor of the pancreas in adult and pediatric patients. Am J Roentgenol 181: 395-401, 2003.

4 Huang HL, Shih SC, Chang WH, Wang TE, Chen MJ and Chan YJ: Solid-pseudopapillary tumor of the pancreas: Clinical experience and literature review. World J Gastroenterol 11: 1403$1409,2005$.

5 Meshikhes AW and Atassi R: Pancreatic pseudopapillary tumour in a male child. JOP 5: 505-511, 2004.

6 Fernandez-del Castillo C and Warshaw AL: Cystic tumours of the pancreas. Surg Clin North Am 75: 1001-1016, 1995.

7 Dong PR, Lu DS, Degregario F, Fell SC, Au A and Kadell BM: Solid and papillary neoplasm of the pancreas: Radiological pathological study of five cases and review of the literature. Clin Radiol 51: 702-705, 1996.

8 Stömmer P, Kraus J, Stolte M and Giedl J: Solid and cystic pancreatic tumors. Clinical, histochemical, and electron microscopic features in ten cases. Cancer 67: 1635-1641, 1991.

9 Nishihara K, Nagoshi M, Tsuneyoshi M, Yamaguchi K and Hayasshi I: Papillary cystic tumours of the pancreas. Assessment of their malignant potential. Cancer 71: 82-92, 1993.

10 Ohashi K, Nakajima Y, Hisanaga M, Nakano H, Tsutsumi M, Kondoh S and Konishi Y: A solid and papillary (solid-cystic) tumor of the pancreas occurring in a 36-year-old man: Report of case. Surg Today 23: 551-555, 1993.

11 Ohiwa K, Igarashi M, Nagasue N, Nagasaki M and Harada T: Solid and cystic tumor (SCT) of the pancreas in an adult man. HPB Surg 10: 315-321, 1997.

12 Wilson MB, Adams DB, Garen PD and Gansler TS: Aspiration cytologic, ultrastructural, and DNA cytometric findings of solid and papillary tumor of the pancreas. Cancer 69: 2235-2243, 1992.

13 Kuo TT, Su IJ and Chien CH: Solid and papillary neoplasm of the pancreas. Report of three cases from Taiwan. Cancer 54: 1469-1474, 1984.

14 Oertel JE, Mendelsohn G and Compagno J: Solid and papillary epithelial neoplasms in of the pancreas. In: Pancreatic tumors in children. (Humphrey GB, Grindey GB, Dehner LP, Acton RT, Pysher TJ) Den Haag: Martinus Nijhoff, pp. 167-171, 1982.

15 Sanchez JA, Newman KD, Eichelberger MR and Nauta RJ: The papillary-cystic neoplasm of the pancreas. An increasingly recognized clinicopathologic entity. Arch Surg 125: 1502-1505, 1990.

16 Orlando CA, Bowman RL and Loose JH: Multicentric papillarycystic neoplasm of the pancreas. Arch Pathol Lab Med 115: 958960, 1991. 
17 Matsunou $\mathrm{H}$ and Konishi F: Papillary-cystic neoplasm of the pancreas. A clinicopathologic study concerning the tumor aging and malignancy of nine cases. Cancer 65: 283-291, 1990.

18 Cappellari JO, Geisinger KR, Albertson KR, Wolfman NT and Kute TE: Malignant papillary cystic tumor of the pancreas. Cancer 66: 193-198, 1990.

19 Horisawa M, Niinomi N, Sato T, Yokoi S, Oda K, Ichikawa M and Hayakawa S: Frantz's tumor (solid and cystic tumor of the pancreas) with liver metastasis: Successful treatment and longterm follow-up. J Pediatr Surg 30: 724-726, 1995.

20 Santini D, Poli F and Lega S: Solid-papillary tumors of the pancreas: Histopathology. JOP 7: 131-136, 2006.

$21 \mathrm{He}$ S, Yang X, Zhou P, Cheng Y and Sun Q: Solid pseudopapillary tumor: An invasive case report of primary ovarian origin and review of the literature. Int J Clin Exp Pathol 8: 8645-8649, 2015.

22 Coleman KM, Doherty MC and Bigler SA: Solid pseudopapillary tumor of the pancreas. Radiographics 23: 1644$1648,2003$.

23 Kloppel G, Solcia E, Longnecker DS, Capella C, Sobin LH and World Health Organization: Institutional histological classification of tumors. Histological typing of tumors of the exocrine pancreas. 2nd ed. Berlin: Springer-Verlag, pp. 14, 1996.

24 Mulkeen AL, Yoo PS and Cha C: Less common neoplasms of the pancreas. World J Gastroenterol 12: 3180-3185, 2006.

25 Lam KY, Lo CY and Fan ST: Pancreatic solid-cystic-papillary tumor: Clinicopathologic features in eight patients from Hong Kong and review of the literature. World J Surg 23: 1045-1050, 1999.

26 Pettinato G, Di Vizio D, Manivel JC, Pambuccian SE, Somma P and Insabato L: Solid pseudopapillary tumor of the pancreas: A neoplasm with distinct and highly characteristic cytological features. Diagn Cytopathol 27: 325-334, 2002.

27 Springer S, Wang Y, Dal Molin M, Masica DL, Jiao Y, Kinde I, Blackford A, Raman SP, Wolfgang CL, Tomita T, Niknafs N, Douville C, Ptak J, Dobbyn L, Allen PJ, Klimstra DS, Schattner MA, Schmidt CM, Yip-Schneider M, Cummings OW, Brand RE, Zeh HJ, Singhi AD, Scarpa A, Salvia R, Malleo G, Zamboni G, Falconi M, Jang JY, Kim SW, Kwon W, Hong SM, Song KB, Kim SC, Swan N, Murphy J, Geoghegan J, Brugge W, Fernandez-Del Castillo C, Mino-Kenudson M, Schulick R, Edil BH, Adsay V, Paulino J, van Hooft J, Yachida S, Nara S, Hiraoka N, Yamao K, Hijioka S, van der Merwe S, Goggins M, Canto MI, Ahuja N, Hirose K, Makary M, Weiss MJ, Cameron J, Pittman M, Eshleman JR, Diaz LA Jr., Papadopoulos N, Kinzler KW, Karchin R, Hruban RH, Vogelstein B and Lennon AM: A combination of molecular markers and clinical features improve the classification of pancreatic cysts. Gastroenterology 149: 1501-1510, 2015.

28 Martin RC, Klimstra DS, Brennan MF and Conlon KC: Solid pseudopapillary tumor of the pancreas: A surgical enigma? Ann Surg Oncol 9: 35-40, 2002.

29 Eder F, Schulz HU, Röcken C and Lippert H: Solid pseudopapillary tumor of the pancreatic tail. World J Gastroenterol 11: 4117-4119, 2005.
30 Salvia R, Bassi C, Festa L, Falconi M, Crippa S, Butturini G, Brighenti A, Capelli P and Pederzoli P: Clinical and biological behavior of pancreatic solidpseudopapillary tumors: Report on 31 consecutive patients. J Surg Oncol 95: 304-310, 2007.

31 Yoon DY, Hines OJ, Bilchik AJ, Lewin K, Cortina G and Reber HA: Solid and papillary epithelial neoplasms of the pancreas: Aggressive resection for cure. Am Surg 67: 1195-1199, 2001.

32 Zinner MJ, Shurbaji MS and Cameron JL: Solid and papillaryepithelial neoplasms of the pancreas. Surgery 108: 475480, 1990.

33 Frago R, Fabregat J, Jorba R, Garcia-Borobia F, Altet J, Serrano MT and Valls C: Solid pseudopapillary tumors of the pancreas: Diagnosis and curative treatment. Rev Esp Enferm Dig 98: 809816, 2006.

34 Ansari NA, Ramalho M, Semelka RC, Buonocore V, Gigli S and Maccioni F: Role of magnetic resonance imaging in the detection and characterization of solid pancreatic nodules: An update. World J Radiol 7: 361-374, 2015.

35 Mergo PJ, Helmberger TK, Buetow PC, Helmberger RC and Ros PR: Pancreatic neoplasms: MR imaging and pathologic correlation. Radiographics 17: 281-301, 1997.

36 Christein JD, Smoot RL and Farnell MB: Central pancreatectomy: A technique for the resection of pancreatic neck lesions. Arch Surg 141: 293-299, 2006.

37 Kim MJ, Choi DW, Choi SH, Heo JS and Sung JY: Surgical treatment of solid pseudopapillary neoplasms of the pancreas and risk factors for malignancy. Br J Surg 101: 1266-1271, 2014.

38 Zauls JA, Dragun AE and Sharma AK: Intensity-modulated radiation therapy for unresectable solid pseudopapillary tumor of the pancreas. Am J Clin Oncol 29: 639-640, 2006.

39 Levy C, Pereira L, Dardarian T and Cardonick E: Solid pseudopapillary pancreatic tumor in pregnancy. A case report. $\mathrm{J}$ Reprod Med 49: 61-64, 2004.

40 Yee AM, Kelly BG, Gonzalez-Velez JM and Nakakura EK: Solid pseudopapillary neoplasm of the pancreas head in a pregnant woman: Safe pancreaticoduodenectomy postpartum. J Surg Case Rep 2015(8): pii: rjv108, 2015.

41 Huang SC, Wu TH, Chen CC and Chen TC: Spontaneous rupture of solid pseudopapillary neoplasm of the pancreas during pregnancy. Obstet Gynecol 121(2 Pt 2 Suppl 1): 486-488, 2013.

42 MacDonald F, Keough V, Huang WY and Molinari M: Surgical therapy of a large pancreatic solid-pseudopapillary neoplasm during pregnancy. BMJ Case Rep 2014: pii: bcr2013202259, 2014. 